\title{
Real-life glycaemic profiles in non-diabetic individuals with low fasting glucose and normal $\mathrm{HbA}_{1 \mathrm{c}}$ : the $\mathrm{A1C}$-Derived Average Glucose (ADAG) study
}

\author{
R. Borg • J. C. Kuenen • B. Carstensen $\cdot$ H. Zheng $\cdot$ D. M. Nathan $\cdot$ R. J. Heine • \\ J. Nerup $\cdot$ K. Borch-Johnsen $\cdot$ D. R. Witte $\cdot$ on behalf of the ADAG Study Group
}

Received: 16 February 2010 / Accepted: 9 March 2010/Published online: 16 April 2010

(C) The Author(s) 2010. This article is published with open access at Springerlink.com

\begin{abstract}
Aims/hypothesis Real-life glycaemic profiles of healthy individuals are poorly studied. Our aim was to analyse to what extent individuals without diabetes exceed OGTT thresholds for impaired glucose tolerance (IGT) and diabetes. Methods In the A1C-Derived Average Glucose (ADAG) study, 80 participants without diabetes completed an intensive glucose monitoring period of 12 weeks. From these data, we calculated the average $24 \mathrm{~h}$ glucose exposure as time spent above different plasma glucose thresholds. We also derived indices of postprandial glucose levels, glucose variability and $\mathrm{HbA}_{1 \mathrm{c}}$.

Results We found that $93 \%$ of participants reached glucose concentrations above the IGT threshold of $7.8 \mathrm{mmol} / \mathrm{l}$ and
\end{abstract}

Electronic supplementary material The online version of this article (doi:10.1007/s00125-010-1741-9) contains a list of members of ADAG Study Group, which is available to authorised users.

R. Borg $(\bowtie) \cdot$ B. Carstensen $\cdot$ J. Nerup $\cdot$ K. Borch-Johnsen ·

D. R. Witte

Steno Diabetes Center,

Niels Steensens Vej 2-4,

DK-2820 Gentofte, Denmark

e-mail: RBrg@steno.dk

J. C. Kuenen · R. J. Heine

VU University Medical Center,

Amsterdam, the Netherlands

R. J. Heine

Eli Lilly and Company,

Indianapolis, IN, USA

H. Zheng • D. M. Nathan

Diabetes Center and Biostatistics Department,

Massachusetts General Hospital and Harvard Medical School,

Boston, MA, USA spent a median of $26 \mathrm{~min} /$ day above this level during continuous glucose monitoring. Eight individuals $(10 \%)$ spent more than $2 \mathrm{~h}$ in the IGT range. They had higher $\mathrm{HbA}_{1 \mathrm{c}}$, fasting plasma glucose (FPG), age and BMI than those who did not. Seven participants $(9 \%)$ reached glucose concentrations above $11.1 \mathrm{mmol} / 1$ during monitoring. Conclusions/interpretation Even though the non-diabetic individuals monitored in the ADAG study were selected on the basis of a very low level of baseline FPG, $10 \%$ of these spent a considerable amount of time at glucose levels considered to be 'prediabetic' or indicating IGT. This highlights the fact that exposure to moderately elevated glucose levels remains under-appreciated when individuals are classified on the basis of isolated glucose measurements.

Keywords Continuous glucose monitoring .

Glucose monitoring - Glycaemia in healthy individuals .

Non-diabetic glucose exposure $\cdot$ Normoglycaemia

$\begin{array}{ll}\text { Abbreviations } \\ \text { ADAG } & \text { A1C-Derived Average Glucose } \\ \text { CGM } & \text { Continuous interstitial glucose monitoring } \\ \text { FPG } & \text { Fasting plasma glucose } \\ \text { IGT } & \text { Impaired glucose tolerance } \\ \text { IQR } & \text { Interquartile range }\end{array}$

Introduction

Current understanding of normoglycaemia is largely based on studies of populations without diabetes, often with a small number of glucose measurements per individual. This results in limited insight into patterns of real-life glycaemia as experienced by healthy individuals. As new options in diabetes treatment increasingly focus on specific glucose 
profiles such as postprandial glycaemia, it is important to have a clearer understanding of what constitutes a normal glucose profile. Knowledge of how much time normoglycaemic individuals spend at different levels of glycaemia under real-life conditions is needed to serve as a benchmark for the more detailed study of impaired glycaemic states and the ability of novel treatments to normalise glucose profiles.

We therefore studied the glucose profiles of non-diabetic individuals who participated in the A1C-Derived Average Glucose (ADAG) study. This observational study included continuous interstitial glucose monitoring (CGM) under real-life conditions. Our aim was to analyse to what extent individuals without diabetes exceed OGTT thresholds for impaired glucose tolerance (IGT) and diabetes [1].

\section{Methods}

Study participants The ADAG study was conducted at ten centres in the USA, Europe and Africa from 2006 to 2008. The aim was to define the relationship between $\mathrm{HbA}_{1 \mathrm{c}}$ and average glucose levels. A full description of the study has been published [2]. The population for the present analysis consisted of the 80 non-diabetic control participants who completed the intensive glucose monitoring period of 12 weeks. The non-diabetic participants were selected on the basis of having no history of diabetes, a plasma glucose level $\leq 5.4 \mathrm{mmol} / \mathrm{l}(97 \mathrm{mg} / \mathrm{dl})$ after an overnight fast and $\mathrm{HbA}_{1 \mathrm{c}}<6.5 \%$. The plasma glucose cut-off was chosen due to its high specificity for excluding diabetes without performing an OGTT [3].

The study was approved by the human studies committees at the participating institutions, and informed consent was obtained from all participants.

Assessing glycaemia Glucose levels were assessed with two different methods during the study period. CGM (Medtronic Minimed, Northridge, CA, USA) was performed for at least $48 \mathrm{~h}$ at baseline and three times at 4 week intervals during the 12 week study period. Participants also measured an eight-point self-monitored blood glucose profile (preprandial, $90 \mathrm{~min}$ postprandial, pre-bedtime and 03:00 hours) using a handheld glucose meter (Glucose 201 Plus; HemoCue, Ängelholm, Sweden) during the days of CGM. This protocol yielded approximately 2,300 glucose values for each participant. The median time of CGM was $230 \mathrm{~h}$ per participant. All glucose concentrations presented are plasma glucose equivalents.

As an indicator of overall hyperglycaemia, the time spent above selected glucose thresholds was calculated for the first $24 \mathrm{~h}$ of each CGM monitoring period after the initial $2 \mathrm{~h}$ calibration period. The mean of these time periods was used. This was done for glucose concentrations corresponding to the different cut-off points in the diagnostic criteria, i.e. $6.1,7.0,7.8,11.1$ and $16.7 \mathrm{mmol} / 1$ (110, 126, 140, 200 and $300 \mathrm{mg} / \mathrm{dl}$, respectively).

Pre- and postprandial measurements for self-monitored blood glucose (HemoCue) were used to calculate mean preand postprandial plasma glucose. Pre-breakfast plasma glucose was defined as fasting plasma glucose (FPG). $\mathrm{HbA}_{1 \mathrm{c}}$ samples were analysed with four highly intercorrelated, DCCT-aligned assays, all of which have been approved by the National Glycohemoglobin Standardization Program (www.ngsp.org/, accessed 1 February 2010). The mean value at the end of the 12 week study period was used [2].

\section{Results}

The study population had a mean age of 41 years (SD 13.8); $69 \%$ were women and $68 \%$ white, with mean $\mathrm{HbA}_{1 \mathrm{c}}$ of $5.2 \%$ (SD 0.3 ), and mean BMI of $25.9 \mathrm{~kg} / \mathrm{m}^{2}$ (5.5) for men and $25.0 \mathrm{~kg} / \mathrm{m}^{2}$ (3.3) for women.

During the monitoring period, median FPG was $5.3 \mathrm{mmol} / 1$ with an interquartile range (IQR) of 4.9 to $5.6 \mathrm{mmol} / \mathrm{l}$. Median preprandial plasma glucose was $5.3 \mathrm{mmol} / \mathrm{l}$ (IQR 5.1-5.6 mmol/l) and median postprandial plasma glucose was $6.0 \mathrm{mmol} / \mathrm{l}$ (IQR 5.7-6.3 mmol/l). Glucose variability during CGM, measured as mean (SD), was $0.8 \mathrm{mmol} / 1(0.2)$.

Table 1 shows the proportion of participants who reached selected glucose thresholds at any time during CGM measurement and the time these participants spent above each threshold. Figure 1 shows distribution of the time spent by individuals above selected glucose concentrations. Participants reaching at least $7.8 \mathrm{mmol} / 1$ spent a median of $31 \mathrm{~min} /$ day (range $0-412 \mathrm{~min}$ ) above this IGT level. A quarter of the total cohort experienced glucose levels

Table 1 Time (per 24 h CGM period) spent above selected plasma glucose concentrations

\begin{tabular}{lcll}
\hline PG, mmol/l (mg/dl) & $\begin{array}{l}\text { Participants } \\
\text { reaching PG } \\
\text { level } l^{\mathrm{a}} \%(n)\end{array}$ & $\begin{array}{l}\text { Median time } \\
\text { above PG } \\
\text { level (min) })^{\mathrm{a}, \mathrm{b}}\end{array}$ & $\mathrm{IQR}^{\mathrm{b}}(\mathrm{min})$ \\
\hline$>6.1(110)$ & $100(80)$ & 395 & $273-688$ \\
$>7.0(126)$ & $99(79)$ & 109 & $45-200$ \\
$>7.8(140)$ & $93(74)$ & 31 & $11-81$ \\
$>11.1(200)$ & $9(7)$ & 8 & $3-62$ \\
$>16.7(300)$ & $1(1)$ & 32 & - \\
\hline
\end{tabular}

${ }^{\text {a }}$ PG level specified in column 1

${ }^{\mathrm{b}}$ For participants reaching specific PG level

IQR, interquartile range; $P G$, plasma glucose 
Fig. 1 Proportion of individuals spending time with plasma glucose concentrations above selected glucose thresholds (per $24 \mathrm{~h}$ monitoring period) of a $7.8 \mathrm{mmol} / 1$, b $11.1 \mathrm{mmol} / 1$ and c $16.7 \mathrm{mmol} / \mathrm{l}$
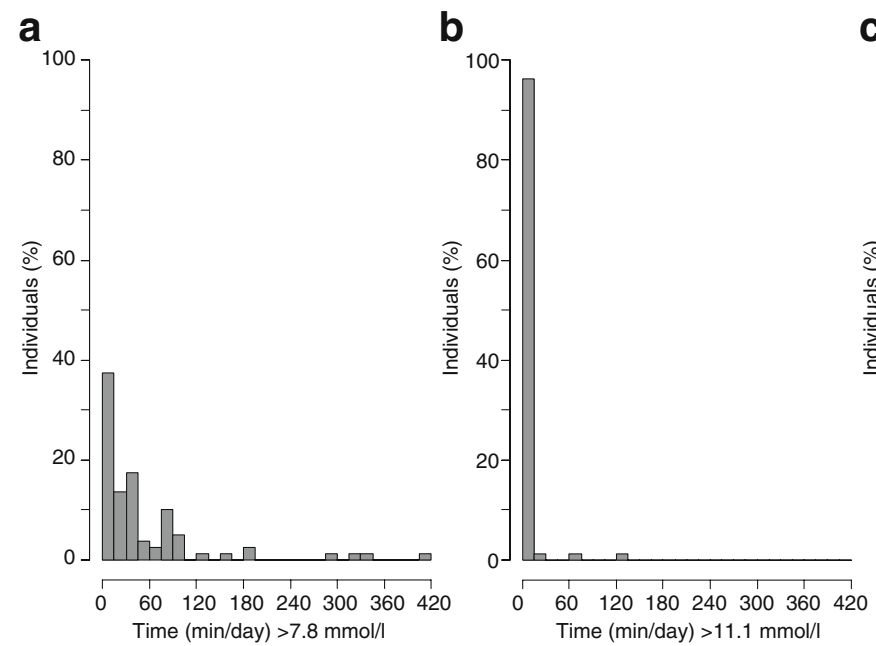

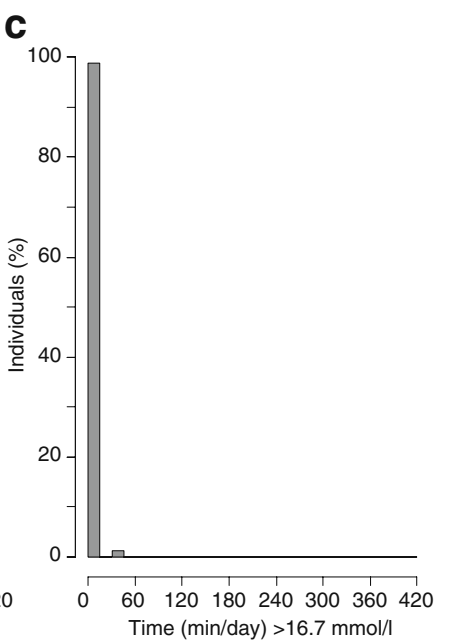

above this threshold for at least $75 \mathrm{~min} / \mathrm{day}$, and three individuals (3.8\%) remained in this range for $5 \mathrm{~h}$ or more per day. These three individuals had $\mathrm{HbA}_{1 \mathrm{c}}$ levels in the normal range $(5.4-5.7 \%)$ and mean FPG between 4.9 and $6.5 \mathrm{mmol} / \mathrm{l}$. The eight individuals who spent more than $2 \mathrm{~h}$ above the IGT cut-off had higher mean $\mathrm{HbA}_{1 \mathrm{c}}(5.7 \%)$, FPG (6.1 mmol/l), age (55 years) and BMI (women $29 \mathrm{~kg} / \mathrm{m}^{2}$, men $30 \mathrm{~kg} / \mathrm{m}^{2}$ ) than those who did not. The proportion of non-white participants and women (six of eight for both) was higher than in the whole study population. Seven persons (9\%) reached $11.1 \mathrm{mmol} / \mathrm{l}$, with two individuals spending more than $1 \mathrm{~h} / 24 \mathrm{~h}$ above this diabetic level.

\section{Discussion}

We found that nearly all individuals without diabetes exceeded the IGT threshold of $7.8 \mathrm{mmol} / \mathrm{l}(140 \mathrm{mg} / \mathrm{dl})$ at some point during the day and spent a median of $26 \mathrm{~min}$ (range $0 \mathrm{~min}$ to $6 \mathrm{~h} 52 \mathrm{~min}$ ) per day above this level. We also found that one in ten individuals reached diabetic levels $(11.1 \mathrm{mmol} / \mathrm{l}, 200 \mathrm{mg} / \mathrm{dl})$. These findings suggest that glucose levels in persons without diabetes frequently reach IGT range concentrations and that a considerable proportion reach diabetic levels. Previous smaller studies have suggested similar patterns, albeit in more homogeneous populations. A study in 32 individuals with confirmed normal glucose tolerance found that seven participants (22\%) reached glucose concentrations above $11.1 \mathrm{mmol} / 1$ (200 mg/dl) during an average of 28 days of CGM and that participants spent on average $42 \mathrm{~min} /$ day at glucose concentrations above $7.8 \mathrm{mmol} / 1(140 \mathrm{mg} / \mathrm{dl})$ [4]. In a smaller study, 15 hospital staff without known diabetes and monitored by CGM for $24 \mathrm{~h}$ were found to spend an average of $72 \mathrm{~min} /$ day with glucose levels higher than $7.0 \mathrm{mmol} / \mathrm{l}(126 \mathrm{mg} / \mathrm{dl})$ [5].

During a standardised OGTT, it is well established that glucose concentrations can exceed $7.8 \mathrm{mmol} / 1$ in individ- uals with normal glucose tolerance in the time preceding the $2 \mathrm{~h}$ value [6]. However, since the $75 \mathrm{~g}$ OGTT is an extreme glucose load compared with an average mixed meal with regard to glucose concentration and the simple carbohydrate content (fast uptake), our results, which were based on real-life monitoring over a prolonged period, add an important dimension.

The limitations of the current study include the absence of OGTTs to rule out diabetes with certainty or to classify participants as having IGT. Our fasting plasma glucose exclusion criterion has been shown to be highly specific for ruling out diabetes [3], but does not rule out the possibility that some of the participants could have had IGT. In addition, our $\mathrm{HbA}_{1 \mathrm{c}}$ exclusion criterion of $\geq 6.5 \%$ has recently been proposed as the new diagnostic level for diabetes [7]. At 5.2\% (SD 0.3), mean $\mathrm{HbA}_{1 \mathrm{c}}$ in the present population was considerably lower. Factors that cause glucose fluctuations, such as food intake, exercise, stress, or beta cell function and insulin sensitivity, were not examined in this study under free-living conditions. However, the present observations are relevant in public health terms, and to clinicians dealing with individuals with a wide, often unknown array of dietary and physical activity patterns.

Our results confirm that considerable variability of glucose levels exists even among individuals classified as not having diabetes. These findings may lead to speculation on the adequacy of current diagnostic practice and whether the use of multiple glucose measurements at different time points of the day or assessment of $\mathrm{HbA}_{1 \mathrm{c}}$ would identify hyperglycaemic individuals more accurately. However, in the absence of data assessing the impact of these glucose profiles on clinical endpoints, the current study cannot establish whether periods of transient hyperglycaemia are part of normal variability or whether such periods affect the risk of progression to diabetes and development of diabetic complications. 


\section{Conclusion}

When glucose levels are measured under real-life conditions in non-diabetic individuals, as defined by a very low level of $\mathrm{FPG}$ and $\mathrm{HbA}_{1 \mathrm{c}}$ levels below $6.5 \%$, these individuals are seen to spend a considerable amount of time with glucose levels classified as 'dysglycaemic' or even diabetic. Since chronic glucose exposure is considered to be one of the main mediators of long-term outcomes, including microvascular and cardiovascular disease, our findings demonstrate that exposure to moderately elevated glucose levels remains under-appreciated when individuals are classified on the basis of isolated glucose measurements. If no adverse outcomes attend these periods of hyperglycaemia, our findings suggest that it is common for persons who are regarded as 'normoglycaemic' by accepted current definitions to experience transient hyperglycaemia during everyday circumstances.

Acknowledgements The ADAG study was supported by research grants from the American Diabetes Association and the European Association for the Study of Diabetes. Financial support was also provided by Abbott Diabetes Care, Bayer Healthcare, GlaxoSmithKline, sanofi-aventis Netherlands, Merck, Lifescan and Medtronic Minimed. Supplies and equipment were provided by Medtronic Minimed, Lifescan and HemoCue.

The Steno substudy was supported by research grants from the Sehested Hansen Foundation, the Clinical Development Foundation at Steno Diabetes Center and the Danish Diabetes Association.

Duality of interest R. J. Heine is employed by and owns stocks of Eli Lilly and company. K. Borch-Johnsen is head of the Steno
Diabetes Center, a hospital integrated in the Danish National Healthcare Service, but owned by Novo Nordisk. K. Borch-Johnsen holds shares in Novo Nordisk Inc. The other authors have no duality of interest associated with this manuscript.

Open Access This article is distributed under the terms of the Creative Commons Attribution Noncommercial License which permits any noncommercial use, distribution, and reproduction in any medium, provided the original author(s) and source are credited.

\section{References}

1. World Health Organization (1999) Definition, diagnosis and classification of diabetes mellitus and its complications. Report of a WHO consultation, part 1: diagnosis and classification of diabetes mellitus. WHO, Geneva

2. Nathan DM, Kuenen J, Borg R et al (2008) Translating the A1C assay into estimated average glucose values. Diabetes Care 31:1473-1478

3. Kahn R (2003) Follow-up report on the diagnosis of diabetes mellitus. Diabetes Care 26:3160-3167

4. Mazze RS, Strock E, Wesley D et al (2008) Characterizing glucose exposure for individuals with normal glucose tolerance using continuous glucose monitoring and ambulatory glucose profile analysis. Diabetes Technol Ther 10:149-159

5. Derosa G, Salvadeo SAT, Mereu R et al (2009) Continuous glucose monitoring system in free-living healthy subjects: results from a pilot study. Diabetes Technol Ther 11:159-169

6. Abdul-Ghani MA, Tripathy D, DeFronzo RA (2006) Contributions of beta-cell dysfunction and insulin resistance to the pathogenesis of impaired glucose tolerance and impaired fasting glucose. Diabetes Care 29:1130-1139

7. No authors listed (2009) International Expert Committee report on the role of the A1C assay in the diagnosis of diabetes. Diabetes Care 32:1327-1334 